\title{
Avaliações seminais e novas ferramentas genômicas na estimação da fertilidade em touros
}

Wilder Hernando Ortiz-Vega*, MSc, Dr.Sc (c), , Valter Luiz Maciel-Júnior, MSc, Dr.Sc (c), Celia Raquel Quirino, Dr.Sc ${ }_{1}$

Laboratório de reprodução e melhoramento genético animal, Centro de Ciências e Tecnologias Agropecuárias, Universidade Estadual do Norte Fluminense, Rio de Janeiro, Brasil

Recibido: 9 de junio del $2015 \quad$ Aprobado: 11 de noviembre del 2015

* Autor de correspondencia: Ortiz-Vega W.H. Centro de Ciências e Tecnologias Agropecuárias, Universidade Estadual do Norte Fluminense. Avenida Alberto Lamego, 2000, Parque Califórnia, CEP: 28013-602. Campos dos Goytacazes, RJ, Brasil. Tel. (55 22) 2739-7055. Correo electrónico: wilortvet@yahoo.es

Cómo citar este artículo: Ortiz-Vega WH, Maciel-Júnior VL, Quirino CR. Avaliações seminais e novas ferramentas genômicas na estimação da fertilidade em touros. Spei Domus. 2015;11(23):33-45. doi: http://dx.doi.org/10.16925/sp.v11i23.1366

Resumo. Tema e alcance: a estimativa da fertilidade do reprodutor é uma ferramenta importante na escolha do macho, não só porque reflete o estado individual do reprodutor, mas também porque dito resultado influencia o futuro do rebanho. A presente revisão aborda o assunto fertilidade no macho bovino sob a perspectiva da biotecnologia do sêmen. Características: descreve as características seminais que influenciam o potencial reprodutivo e apresenta de forma geral técnicas laboratoriais rotineiras e inovadoras na avaliação de espermatozoides. Documentos base na área de biotecnologia de sêmen assim como artigos das últimas quatro décadas foram utilizados na revisão; além disso, aspectos-chave de manuais e livros de difusão mundial complementam o acervo bibliográfico referenciado. Achados: o amplo número de estudos sobre o tema e a diversidade nos resultados pressupõem vazios no conhecimento que abrem uma oportunidade na utilização de ferramentas genômicas e permitem explicar com maior acurácia os diferentes eventos fisiológicos presentes na expressão das características seminais referentes à fertilidade. Conclusões: a variância genética e as mudanças epigenéticas podem estar influenciando o potencial reprodutivo no macho; fenômenos funcionais ainda pouco conhecidos precisam ser elucidados no intuito de compreender e, talvez, alterar essa variação entre e inter reprodutores.

Palavras-chave: espermatozoide, inseminação artificial, marcador molecular, proteômica. 


\title{
Evaluaciones seminales y nuevas herramientas genómicas en la estimación de la fertilidad en toros
}

Resumen. Tema y alcance: estimar la fertilidad del reproductor es una herramienta importante en la selección del macho, no solo porque refleja el estado individual del reproductor, sino también porque tal resultado influencia el futuro del rebaño. La presente revisión aborda el asunto de la fertilidad en el macho bovino desde la perspectiva de la biotecnología del semen. Características: describe las características seminales que influyen en el potencial reproductivo y plantea, de forma general, técnicas de laboratorio rutinarias e innovadoras para la evaluación de espermatozoides. Documentos base en el área de biotecnología del semen y artículos de las últimas cuatro décadas se utilizaron en la revisión; además de esto, aspectos claves de manuales y libros de difusión mundial complementan el acervo bibliográfico referenciado. Hallazgos: el amplio número de estudios acerca del tema y la diversidad en los resultados presuponen vacíos en el conocimiento que abren una oportunidad en la utilización de herramientas genómicas y permiten explicar con más precisión los distintos eventos fisiológicos presentes en la expresión de las características seminales de fertilidad. Conclusiones: la variación genética y los cambios epigenéticos pueden estar influenciando el potencial reproductivo del macho; fenómenos funcionales aún poco conocidos deben ser aclarados con el fin de comprender y, tal vez, modificar esta variación entre e interreproductores.

Palabras claves: espermatozoide, inseminación artificial, marcador molecular, proteómica.

\section{Seminal Testing and New Genomic Tools in Estimating Fertility in Bulls}

\begin{abstract}
Topic and scope: Estimating the fertility of the breeding animal is an important tool in selecting the male, not only because it reflects the individual state of the breeding animal, but also because such result influences the future of the herd. This review addresses the issue of bovine male fertility from the perspective of semen biotechnology. Features: The seminal characteristics that influence reproductive potential are described, and innovative routine laboratory techniques for sperm testing are proposed in a general way. Base documents in the area of semen biotechnology and articles from the past four decades were used in the review; in addition, key aspects of globally disseminated manuals and books complement the referenced bibliography collection. Findings: The large number of studies on the topic and diverse results presuppose knowledge gaps that open up an opportunity to use genomic tools and allow to explain more precisely the different physiological events present in the expression of seminal characteristics of fertility. Conclusions: Genetic variation and epigenetic changes may be influencing male reproductive potential; functional phenomena that are still little known must be clarified in order to understand and perhaps modify this variation in and among reproductive stock.
\end{abstract}

Keywords: spermatozoon, artificial insemination, molecular marker, proteomics. 


\section{Introdução}

A aplicação de tecnologias de reprodução assistida possibilita o incremento no melhoramento genético. Algumas dessas técnicas aumentam a seleção diferencial fixando características de interesse zootécnico, como a inseminação artificial (IA) e a transferência de embriões, enquanto a produção in vitro de embriões (principalmente a partir de animais pré-púberes) acelera o ganho genético e reduz o intervalo entre gerações [1]. A IA apresenta taxa de prenhez satisfatória, no entanto só $50 \%$ dessas prenhezes conseguem chegar a termo com sucesso [2], aproximadamente a metade dos casos de perda é consequência de infertilidade ou subfertilidade do macho [3].

Durante as últimas décadas, numerosos testes de avaliação da capacidade fertilizante dos espermatozoides foram desenvolvidos, destacando-se as análises morfológicas [4], da motilidade [5], os testes de penetração do muco cervical [6], a análise das membranas plasmática e acrossomal, e a interação espermatozoide-zona pelúcida em testes de fertilização in vitro com oócitos homólogos [7]. Entretanto, é necessário um método preciso e amplamente aplicável para a avaliação de sêmen no diagnóstico de infertilidade do macho que permita melhorar os padrões de avaliação seminal. Estudos genômicos e/ou proteômicos sistematizados das características seminais assim como chips de microarranjos poderiam contribuir na identificação de novas e melhores técnicas de avaliação [8].

O presente estudo de revisão tem como objetivo apresentar de forma geral as principais técnicas e abordagens utilizadas na estimativa de fertilidade seminal em bovinos assim como descrever de forma geral aspectos inovadores com a utilização de ferramentas genômicas.

\section{Avaliação da fertilidade em touros}

A fertilidade é uma característica complexa que compreende desenvolver estágios de conhecimento sobre áreas como: interação do espermatozoide e oócito para formar um zigoto, compactação de células embrionárias para formar uma mórula, estabelecimento do blastocisto, fixação do embrião no útero, desenvolvimento fetal, entre outros [9]. Por sua vez, a queda no desempenho reprodutivo na pecuária bovina ao longo das últimas décadas [10] tem sido atribuída principalmente à falha de fertilização e à perda embrionária precoce [11].
Os touros são capazes de gerar mais descendentes do que as vacas; consequentemente, a seleção do macho é mais eficaz do que a seleção da fêmea para melhorar qualquer característica [12]. Quando se utilizam touros com valores genético e reprodutivo superiores em um rebanho, pode-se reduzir o número de reprodutores em serviço e acelerar o ganho genético [13]. Entretanto, existem diferenças na capacidade fertilizante entre os touros [14]-[17]

Desde 1986, o método mais utilizado no mundo para avaliar a fertilidade do macho na pecuária foi por meio da taxa de concepção relativa estimada (ERCR, do inglês estimated relative conception rate), que se baseava na taxa de não retorno ao cio (NNR, do inglês non-return rate) após o primeiro serviço por IA [18]. De acordo com o modelo proposto por Clay e McDaniel [19], a ERCR é expressa como a diferença percentual do reprodutor na taxa de concepção por IA, em relação à média do grupo contemporâneo.

Essa abordagem depende estritamente da disponibilidade de uma grande quantidade de dados que devem ser corrigidos e padronizados para principais fatores de variabilidade ambiental. Além disso, a estimativa de fertilidade por meio de cruzamentos ou ia é cara e demorada, e só é possível após o uso generalizado de um touro [20].

Devido a questionamentos sobre a acurácia do ERCR, em 2008, foi adotado um novo índice de fertilidade para machos nos Estados Unidos, chamado taxa de concepção do reprodutor (SRC, do inglês sire rate conception), que se baseia na confirmação da prenhez 70 dias após IA (diferente da taxa de retorno ao cio) [21].

A avaliação de características morfológicas do reprodutor é fundamental no diagnóstico de fertilidade. Essa avaliação tem foco na função testicular e do epidídimo, e/ou na normalidade do trato genital do macho, auxiliando a identificação de casos de infertilidade, ou mesmo de sub-fertilidade potencial. Já a avaliação das características seminais pode determinar o seu grau de normalidade, antes do sêmen ser processado para a inseminação artificial ou fertilização in vitro (FIV) [22]. Avaliação da função espermática em uma amostra de sêmen tem um objetivo final de informar sua fertilidade potencial e, em longo prazo, informar a fertilidade do macho de onde a amostra foi coletada [22].

Para medir e até mesmo estimar a fertilidade do macho, diversos métodos laboratoriais foram concebidos durante as últimas décadas, com o objetivo de 
reduzir os custos e o tempo necessário para avaliar touros cujo material genético será difundido por meio de biotecnologias como a IA, principalmente [23].

Parte da complexidade de trabalhar com os espermatozoides provém do fato de cada espermatozoide ser uma célula multicompartimental que deve possuir diferentes atributos para ser capaz de fertilizar um oócito [24]. Dentre as principais características que deve possuir a célula espermática, destacam-se: motilidade, atividade mitocondrial, membrana acrossomal intacta, receptores de membrana, membranas plasmáticas intactas e núcleo em adequado grau de condensação [24, 25, 26].

Devido a essa multicompartimentalidade, a análise de uma característica não é suficiente para estimar a capacidade fertilizante dos espermatozoides, pois o defeito funcional ou morfológico pode se encontrar em qualquer outro local celular [27].

\section{Análise por característica em espermatozoides criopreservados}

\section{Morfologia espermática}

A estrutura do espermatozoide bovino divide-se, principalmente, em quatro regiões: cabeça, peça intermediária, peça principal e peça terminal (figura 1).

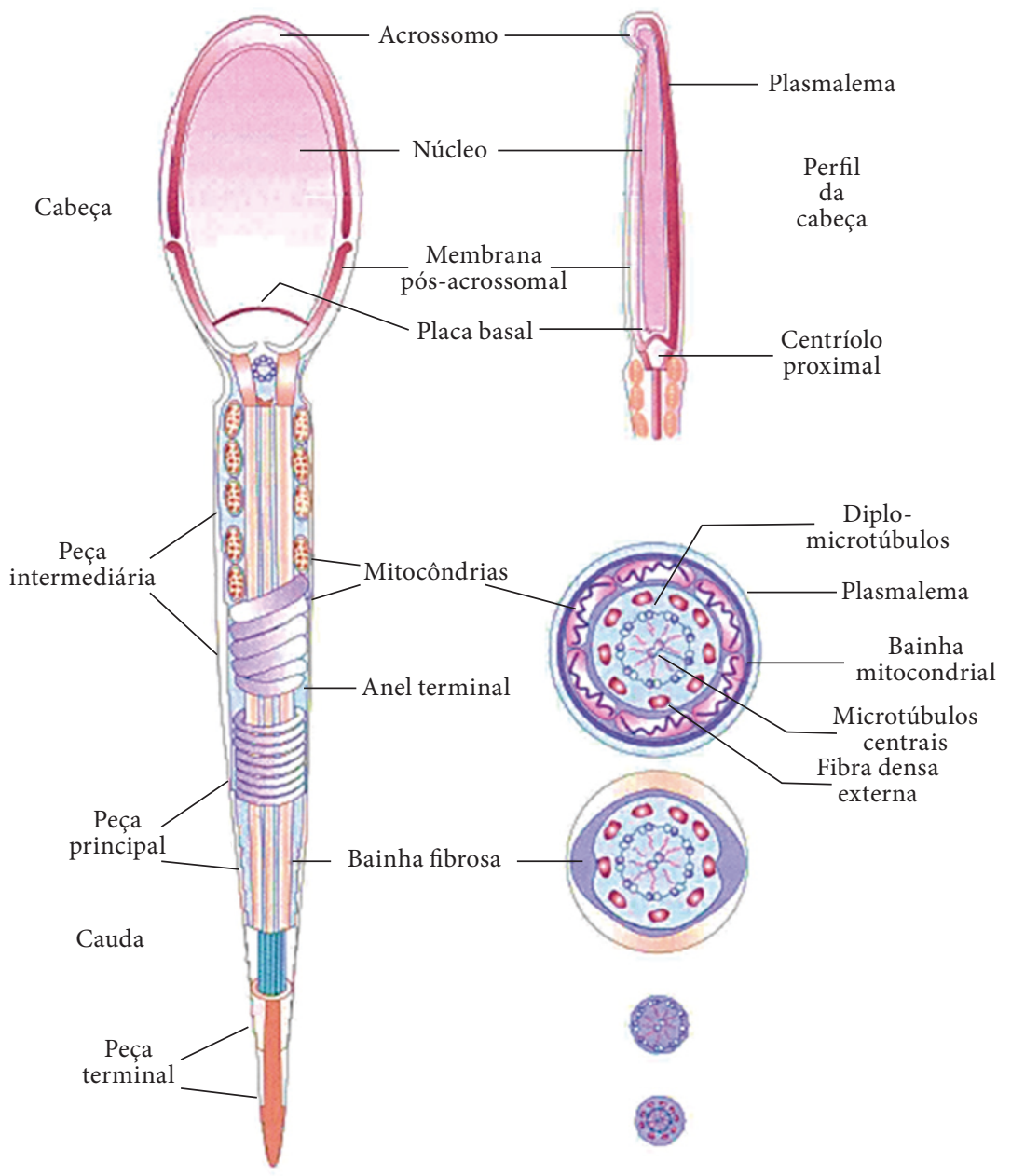

Figura 1. Representação esquemática da estrutura de um espermatozoide bovino Fuente: [28] 
A análise morfológica do sêmen é um importante parâmetro de qualidade e, de modo geral, permite descartar ejaculados ou machos que ultrapassam um determinado nível de anormalidades. Para machos que estão dentro dos padrões tolerados de anormalidades, a morfologia espermática parece ter valor limitado para predição da fertilidade [29]. Nesse sentido, pode-se assumir que a avaliação da morfologia e da motilidade espermática apresentam maior sensibilidade e, portanto, valor prognóstico, quando empregadas na identificação de amostras que naturalmente apresentam baixo potencial de fertilidade [30].

Com relação às diferentes subestruturas e a seu papel determinante na fertilidade, alterações morfológicas na cabeça [31-33], peça intermediária, peça principal [34] e peça terminal dos espermatozoides têm sido relacionadas com queda do potencial fertilizante em touros [35].

Anormalidades dos espermatozoides podem ser divididas em alterações primárias e secundárias ou em alguns sistemas de classificação de anomalias maiores e menores [24]. Portanto, defeitos maiores são aqueles associados com potencial fertilizante diminuído, enquanto defeitos menores têm pouco efeito sobre a fertilidade [36] e geralmente podem ser compensados pela adição de espermatozoides na inseminação (infertilidade compensatória) [32].

Segundo o procedimento de exame andrológico e de avaliação seminal para bovinos descrito pelo Colégio Brasileiro de Reprodução Animal [37], o valor individual máximo comumente aceito para defeitos maiores é de $20 \%$, e a soma destes com defeitos menores não deve superar $30 \%$ em amostras de sêmen de touros doadores. Casagrande et al. [38] reportaram, após avaliar 191 partidas de sêmen bovino com boa fertilidade, menos de $20 \%$ de patologia espermática e $15 \%$ de defeitos maiores, enquanto partidas acima de $30 \%$ de patologia espermática e $20 \%$ de defeitos maiores tiveram baixa fertilidade. Isso é geralmente associado com amostras que contêm números elevados de espermatozoides com anormalidades em cabeça e acrossoma, e presença de vacúolos nucleares.

A morfologia espermática é avaliada subjetivamente por meio de microscopia óptica convencional [39], em que normalmente são contadas 200 células e observadas com ampliação 1000X em microscópio de contraste de fases sob óleo de imersão [40]. Entretanto, para a observação de elementos como a forma do núcleo espermático, são requeridos métodos mais objetivos, por exemplo, a análise computadorizada da morfometria espermática (Asma, do inglês automated sperm morphometry analysis), técnica que pode proporcionar a identificação de touros de baixa fertilidade de forma quantitativa [24].

\section{Integridade da membrana plasmática}

A integridade da membrana plasmática é essencial no processo de fertilização [41] e é comumente associada com viabilidade espermática [42]. A avaliação da integridade física da membrana plasmática pode ser feita por meio de corantes (Azul de Tripan, Eosina/nigrosina) ou sondas fluorescentes (Carboxifluoresceinadiacetato - CFDA, Iodeto de Propideo - PI, sybr-14, Hoechst 33342) [43-45]. No entanto, avaliações da competência funcional da membrana plasmática são realizadas frequentemente pelo teste hiposmótico (Host, do inglês hypoosmotic swelling test) [46].

Quando essa avaliação é associada com o teste de competência funcional (Host) e colorações que avaliam a integridade plasmática e acrossomal, a percentagem de variação da fertilidade explicada superou $80 \%$ [47]. Januskauskas et al. [48], utilizando sondas fluorescentes, consideraram a viabilidade espermática como a variável de maior impacto isolado na determinação de potencial fertilizante.

\section{Integridade da membrana acrossomal}

A capacitação espermática e a reação acrossomal agem como processos conjuntos que os tornam essenciais na aquisição da capacidade de penetração do oócito pelos espermatozoides [30].

$\mathrm{O}$ acrossoma deve ser estrutural e bioquimicamente intacto antes de começar a reação acrossômica. Ele contém as enzimas necessárias para que o espermatozoide possa se ligar, penetrar o oócito e fertilizá-lo [49].

O processo de criopreservação afeta diferencialmente as subpopulações de espermatozoides, levando a uma redução da sua habilidade de penetração na zona pelúcida assim como à predisposição à capacitação prematura e à reação acrossômica (AR) espontânea [50]. O grau de AR está significativa e positivamente relacionado à fertilidade [22]. 
Marcadores fluorescentes como a clortetraciclina (стс) têm sido utilizados para avaliar o percentual de espermatozoides capacitados em uma amostra, mostrando-se como método útil para avaliar mudanças biologicamente relevantes no estado funcional de suspensões de esperma de touros [51]. De modo geral, essa sonda se liga à membrana plasmática do espermatozoide sob sistema $\mathrm{Ca}^{2+} / \mathrm{Mg}^{2+}$ dependente e forma, assim, complexos altamente fluorescentes de Стс com $\mathrm{Ca}^{2+}$ e ions $\mathrm{Mg}^{2+}$ ligados à membrana [52].

As aglutininas como a do Ricinus communis (RCA) e Psium sativum (PSA) possuem especificidade por glicoproteínas da membrana acrossomal e, quando conjugadas ao isotiocianato de fluoresceína (FITC, do inglês fluorescein isothiocyanate), indicam o estado do acrossoma; assim a fluorescência é indicativo de interrupção da membrana acrossomal ou falha na reação acrossômica, e a ausência de fluorescência é indicativo de acrossoma intacto [53, 54, 45]. Outros trabalhos com aglutinina de amendoim conjugada com ficoeritrina (PE-PNA, do inglês phycoerythrin-peanut agglutinin) também mostraram resultados satisfatórios na avaliação desse parâmetro [55].

\section{Avaliação direta da função mitocondrial}

Embora vários estudos mostrassem que o papel das mitocôndrias localizadas na peça intermediária dos espermatozoides não necessariamente são responsáveis pelo fornecimento energético que dá mobilidade à célula espermática [56-58], a avaliação da função delas no espermatozoide continua sendo importante, uma vez que o ATP produzido por elas se relaciona com processos que regulam o gradiente de $\mathrm{Na}^{+} / \mathrm{K}^{+}$nas membranas plasmáticas. Desse modo, sua integridade funcional pode se associar com a sobrevivência do espermatozoide através trato genital feminino ou durante a aplicação de tecnologias de reprodução assistida (ARTS, do inglês assisted reproductive technologies) [54].

As mitocôndrias da peça intermediária produzem ATP por meio da fosforilação oxidativa (via aeróbica). Na produção desse ATP, a ATP sintase catalisa a reação utilizando um sistema de transporte ativo de elétrons que gera uma gradiente negativa de prótons, os quais vão de volta para a matriz mitocondrial, o que leva à produção da molécula de ATP $[59,54]$.
Sondas fluorescentes como Rodhamina $123 \mathrm{e}$ 5,5',6,6'-tetrachloro-1,1',3,3'-tetraethylbenzimidazolyl-carbocyanine iodide (JC-1) são utilizadas na avaliação da função mitocondrial [24, 58].

Na interpretação do princípio de ação das sondas, para mitocôndrias não coradas, assume-se que o gradiente de prótons entrou em colapso e, consequentemente, a produção de ATP aeróbico cessou. Assim, espermatozoides não corados não contêm mitocôndrias funcionais, enquanto as células coradas são positivas ou funcionais $[59,54]$.

Apesar da multiplicidade de sondas disponíveis, JC-1 apresenta vantagens devido a sua capacidade de fixação na membrana mitocondrial interna, o que torna vantajoso na identificação de populações de mitocôndrias com alto e baixo potencial de membrana [45].

\section{Estudo da cromatina espermática}

Características da cromatina em espermatozoides podem contribuir para totipotência celular assim como para o desenvolvimento de padrões de imprinting paterno e ativação do genoma embrionário [60]. Correlação significativa entre fertilidade e anomalias na estrutura do DNA tem sido encontrada em humanos [61-62] e animais [63-64].

Mudanças drásticas na estrutura da cromatina ocorrem durante os estágios finais da espermiogênese em mamíferos. O genoma das espermátides é condensado no núcleo celular e inativado pela ligação sequencial de várias proteínas nucleares básicas [65]. O arranjo da cromatina espermática difere das células somáticas, e essa remodelação nas proteínas básicas confere maior grau de condensação desta. Em bovinos, a proteína comumente associada à cromatina é a Protaminal (P1) [66]. Modelos de organização da protaminas foram propostos décadas atrás [67] e ainda continuam sendo alvo de estudos.

As alterações na integridade da cromatina estão caracterizadas pela presença de rupturas na fita simples ou dupla da molécula de DNA, o que acarreta formação de segmentos desnaturados [63]. Em humanos, danos ao DNA do espermatozoide têm afetado parcialmente o desenvolvimento do embrião e sua capacidade para uma implantação bem-sucedida [68], o que sugere uma perda espontânea da gestação [69].

Foram identificadas quatro principais causas de quebras na estrutura do DNA: 1) apoptose 
abortiva durante mitose inicial, 2) rupturas dos filamentos de DNA não resolvidas e criadas durante a espermatogênese para aliviar as tensões da torção associadas à remodelação da cromatina, 3) maturação espermática anormal causada por distúrbios na protaminação e 4) estresse oxidativo derivado da liberação de radicais livres provenientes do metabolismo celular [70, 71].

Existem várias formas de classificar os testes envolvidos na avaliação da integridade da cromatina espermática. Esses testes podem variar segundo seu mecanismo de ação em: 1) testes que determinam a estrutura da cromatina, como Laranja de Acridina (AO, do inglês acridine orange), Azul de anilina, Cromomicyn A, Azul de Tolouidina e o ensaio estrutural da cromatina espermática (sCSA, do inglês sperm chromatin structure assay); 2) testes de fragmentação do DNA espermático, como tradução de quebras in situ (ISNT, do inglês in situ nick translation), desoxinucleotidiltransferase terminal duTP mediada por quebras de marcação terminal (Tunel, do inglês terminal deoxynucleotidyl transferase duTP nick end labeling), detecção de quebra por hibridação e fluorescência in situ (DBD-fish, do inglês DNA breakage detection-fluorescence in situ hybridization), ensaio de eletroforese em gel de única célula (Cometa) e 3) ensaios espermáticos da matriz nuclear como o teste de dispersão da cromatina ( $\mathrm{SCD}$, do inglês sperm chromatin dispersion) e o teste de estabilidade da matriz nuclear espermática $[62,71]$.

Existe controvérsia entre estudos em humanos $[72,73]$ e bovinos em relação aos testes que avaliam a estrutura da cromatina e sua associação com fertilidade, embora em humanos a técnica SCSA tenha comprovada associação clínica com fertilidade, em bovinos os resultados não são conclusivos [74-76] já que cada teste avalia uma particularidade do dano ao DNA, e o número de avaliações dos ensaios não permite associação estatística.

Finalmente, o alto rendimento das avaliações seminais multiparâmetro (de preferência com a ajuda de detecção por citometria de fluxo e coloração fluorescente) deverão fornecer dados estatisticamente mais fortes que permitam obter correlações entre os parâmetros de qualidade do sêmen e os resultados de fertilidade [54].

\section{Testes in vitro na estimativa da fertilidade}

Ensaios que avaliam a capacidade dos espermatozoides se ligarem à zona pelúcida e/ou penetrar/ fertilizarem os oócitos in vitro foram também desenvolvidos. Eles mensuram a eficácia (concentração e capacidade) de receptores dos espermatozoides para se ligarem ao oócito, ao oolema e iniciarem a fertilização [24].

A IA é o método mais preciso para avaliar a fertilidade de um touro; no entanto, comparada com a fertilização in vitro (FIV), a IA tem como desvantagens seu alto custo e longo período de avaliação [77].

Estudos retrospectivos comumente relatam correlações positivas $(r=0,35-0,59)$ entre FIV e fertilidade in vivo $[78,79]$. Vários autores sugerem que a análise combinada de características de espermatozoides separados por swim-up, ensaio de penetração da zona pelúcida (zBA, do inglês zona binding assay) e FIV pode ser usada para prever a fertilidade do touro [80, 20].

Em estudo recente, o teste de penetração em muco cervical mostrou-se correlacionado com FIV; assim, espermatozoides com reduzida capacidade de penetração no teste apresentaram baixa capacidade fertilizante [81].

Morado et al. [82], avaliando fertilidade in vivo por meio da IA, concluíram que as taxas de FIV foram significativamente maiores nos touros de alta fertilidade in vivo quando comparados com os de baixa fertilidade, considerando a baixa importância relativa dos outros ensaios aplicados neste estudo. Os autores sugerem o teste de FIV como a técnica mais adequada para estimar a fertilidade a campo.

\section{Genômica na predição de fertilidade}

A genômica em bovinos passou por uma mudança de paradigma desde o advento do sequenciamento do genoma, que inclui, entre outras abordagens, estudos de associação ampla do genoma (GWAS, do inglês genome-wide association studies). Essa ferramenta colabora para desvendar a genética de características complexas e fornecer previsões biologicamente significativas e precisas [83].

A aplicação de tecnologias da genômica para estudo da célula espermática, em conjunto com uma avaliação detalhada da competência funcional deve fornecer perspectivas para as bases bioquímica, fisiológica e genética da qualidade do sêmen de baixo potencial fertilizante [61].

Abordagens genômicas comparativas que identificam genes expressos nos testículos têm caracterizado genes com importantes funções na 
regulação do desenvolvimento espermático em diferentes espécies (murinos, insetos, humanos e bovinos principalmente) $[84,85]$.

\section{Proteômica}

Amplos e dinâmicos estudos de proteômica e genômica comparativa são um pré-requisito para identificar novos biomarcadores para fertilidade masculina que serão subsequentemente aplicáveis na determinação da fertilidade [86].

Touros classificados como de alta e baixa fertilidade apresentaram diferente perfil de proteínas do plasma seminal (вPss) [87]-[88]. Killian [88] identificou alta e positiva correlação entre fertilidade e BSP 30kd, fosfolipase A2 e osteopontina, enquanto touros com baixa fertilidade tiveram alta concentração de espermadesina Z13.

D'Amours et al. [89] identificaram duas proteínas (adenilatoquinase isoenzima 1 e proteína de ligação fosfatidiletanolamina 1), principalmente expressas em touros com espermatozoides férteis e conseguiram explicar $64 \%(p<0,001)$ das pontuações de fertilidade do respectivo touro.

Park et al. [90] identificaram cinco proteínas, enolase 1 (ENO1), ATP $\mathrm{H}^{+}$sintase (АTP5B), ASPP2, alfa2-HS-glicoproteina (AHSG), e fosfolipídio hidroperóxido glutation peroxido (GPX4), expressas em maior proporção nos espermatozoides de touros de alta fertilidade, enquanto três proteínas, VDAC2, ropporin-1, e UQCRC2, foram mais altamente representadas nos espermatozoides de touros de fertilidade baixa. Neste estudo, o limite inferior da alta fertilidade foi definido como taxa de não retorno ao cio maior a $70 \%$.

RNAS de espermatozoides também fornecem uma alternativa para entender o desenvolvimento de cada célula e proporcionam, assim, biomarcadores de fertilidade e prenhez. $\mathrm{O}$ rápido desenvolvimento das tecnologias de ensaio RNA que incluem RNA-seq tem detalhado a presença específica de uma ampla variedade de transcritos dos espermatozoides. Essas transcrições não somente parecem refletir o curso passado da espermatogênese, mas também incluir fatores críticos para a fertilização bem-sucedida e o desenvolvimento embrionário [91].

Rahman et al. [92] apresentam um resumo dos principais estudos de proteômica para definir a fertilidade masculina com modelos animais.

\section{Marcadores de DNA}

Apesar da conhecida influência do macho na reprodução e do seu impacto no rebanho, ainda são poucos os estudos que comparam características de fertilidade em relação aos estudos desenvolvidos com fêmeas [93].

A identificação de polimorfismos de único nucleotídeo (sNPs, do inglês single-nucleotide polymorphisms) para genes específicos envolvidos na reprodução pode melhorar a confiabilidade das estimativas genômicas para essas características de baixa herdabilidade [94].

Recentemente, painéis de genotipagem que contêm milhares de marcadores estão sendo empregados nas análises de associação para identificação de Locos de Características Quantitativas (QTLS, do inglês Quantitative Trait Loci). Essa técnica, chamada de estudo de associação genômica ampla (genome-wide association studies - GWAss), explora o desequilíbrio de ligação dos milhares de marcadores que cobrem o genoma animal [95] de forma que todos os genes de um QTL estejam em desequilíbrio de ligação com pelo menos uma parte dos marcadores, explicando assim quase a totalidade da variação genética de um caráter quantitativo.

Quando genes são selecionados baseados na sua posição no genoma (sobre loci de característica quantitativa ou QTL), tornam-se candidatos; então, são avaliados marcadores genéticos na região cromossômica específica que devem ser testados em outras populações a fim de definir o QTL como segregante [96].

O estudo de associação genômica ampla tem gerado valiosas informações sobre a fisiologia reprodutiva de machos nas diferentes espécies de mamíferos uma vez que avaliam o genoma em sua totalidade permitem a identificação de genes candidatos assim como a comparação entre espécies nos eventos fisiológicos avaliados [97]. Estes autores identificaram o gene integrina beta 5 (ITGB5) como importante na interação entre espermatozoide e oócito, afetando, assim, fertilização e desenvolvimento embrionário inicial.

Fortes et al. [98], utilizando GWAs em uma população de touros Brahman, identificaram genes associados a características reprodutivas como desenvolvimento testicular e qualidade seminal, assim como para os hormônios reprodutivos IGF1, LH e inibina. 
Apesar do reconhecido papel do macho na fertilização e no desenvolvimento embrionário descrito por diversos autores $[15,95,99]$, ferramentas genômicas de seleção para a característica fertilidade espermática são escassas nos diferentes programas de melhoramento genético [100].

Recentemente foram descobertas associações significativas entre SNPS do macho e taxa de prenhez em três genes relacionados com espermatogênese (MAP1B, PPP1R11 e DDX4). Seis marcadores SNPS associados aos genes citados foram propostos como marcadores genéticos em etapa de prova para avaliação em outras populações [98].

\section{Conclusões}

Durante décadas, a estimativa de fertilidade no macho tem sido auxiliada com a utilização dos testes laboratoriais. $\mathrm{O}$ avanço no desenvolvimento de técnicas, a difusão destas e a diminuição dos custos fazem com que hoje existam rotinas nas centrais de coleta de sêmen que, de alguma maneira, predizem o potencial fertilizante de uma amostra espermática.

No entanto, causas de infertilidade ou subfertilidade não compensatórias no macho são multifatoriais e podem afetar as diferentes etapas do desenvolvimento espermático. Portanto, a estimativa do potencial fertilizante de amostras procedentes de animais com esse tipo de características exige abordagens mais conclusivas, que expliquem a variância genética e epigenética reguladora dos mecanismos associados aos parâmetros seminais essenciais no processo de fertilização em amostras de sêmen bovino.

\section{Referências}

[1] Baldassarre H, Karatzas C. Advanced assisted reproduction technologies (ART) in goats. Anim Reprod Sci. 2004;(83):255-6.

[2] Watson PF. The causes of reduced fertility with cryopreserved semen. Anim. Reprod. Sci. 2000;(6061):481-92.

[3] Moore FL, Reijo-Pera RA. Male sperm motility dictated by mother's mt DNA. Am. J. Hum. Genet. 2000;(67):543-8. doi: 10.1086/303061
[4] Bonde JP, Ernst E, Jensen TK, Hjollund NH, Kolstad $\mathrm{H}$, Henriksen TB, et al. Relation between semen quality and fertility: a population-based study of 4 first-pregnancy planners. Lancet. 1998;(352):1172-7.

[5] Budworth PR, Amann RP, Chapman, PL. Relationships between computerized measurements of motion of frozen-thawed bull spermatozoa and fertility. J Androl. 1998;(9):41-54.

[6] Aitken RJ, Sutton M, Richardson DW, Warner P. Relationship between the movement characteristics of human spermatozoa and their ability to penetrate cervical mucus and zona-free hamster oocytes. J Reprod. Fertil. 1985;(73):441-9.

[7] Guienne B, Humbolt P, Thibier M, Thibault C. Evaluation of bull semen fertility by homologous in vitro fertilization tests. Reprod. Nutr. Dev. 1990;(30):259-66.

[8] Corner JS, Barratt CR. Genomic and proteomic approaches to defining sperm. Em: De Jonge, C; Barrat, C.The Sperm Cell. Cambridge University Press. Cambridge, 2006.p. 49-71.

[9] Amann R, DeJarnette J. Impact of genomic selection of AI dairy sires on ther likely utilization and methods to estimate fertility: A paradigm shift. Theriogenology. 2012;(77):795-817. doi: 10.1016/j.theriogenology.2011.09.002

[10] Dobson H, Smith R, Royal M, Knight C, Sheldo, I. The higth prodution dairy cow and its reproductive performance. Reprod. Domest. Anim. 2007;42(Suppl 2)17-23. doi: 10.1111/j.1439-0531.2007.00906.x

[11] Santos J, Thatcher W, Chebel R, Cerri R, Galvão K. The effect of embryonic death rates in cattle on the efficacy of estrus sychronization programs. Anim. Reprod. Sci. 2004;83:513-35.

[12] McDanield T, Kuehn L. Male Chromosome Hinders Female Cattle Reproduction. Agricultural Research. 2014;62(4):12-3.

[13] Fordyce G, Fitzpatrick L, Cooper N, Doogan VJ, De Faveri J, Holroyd R. Bull selection and use in Northem Australia. Social Behaviour and management. Animal Reproduction Science. 2002;71(1-2):81-99.

[14] Miller DJ, Hunter AG. Individual Variation for In Vitro Fertilization Success in Dairy Bulls. J Dairy Sci. 1987;(70):2150-3.

[15] Aoyagil Y, Fujii K, Iwazumi Y, Furudate M, Fukui Y, Ono H. Effects of two treatments on semen from different bulls on in vitro fertilization results of bovine oocytes. Theriogenology. 1988;30(5):973-85.

[16] DeJarnette J, Saacke R, Bame J, Vogler C. Accessory sperm: their importance to fertility and embryo quality, and attempts to alter their numbers in artificially inseminated cattle. J ANIM SCI. 1992;(70):484-91. 
[17] Zodinsanga P, Mavi P, Cheema R, Kumar A, Gandotra V. Relationship Between Routine Analysis/Sperm Function and Fertility Test of Catle Bull semen. Asian Journal of Animal Science. 2015;9(1):1819-78. doi: 10.3923/ajas.2015.37.44.

[18] Clay J. How ERCR's will be computed and published. Dairy genetics and reproductive management cow college. Blackbug: Virginia Polytchnic Inst State Univ; 1987.

[19] Clay J, McDaniel B. Computing mating bull fertility from DHI nonreturn data. J. Dairy Sci. 2001;(84):1238-45.

[20] Puglisi R, Pozzi A, Foglio L, Spanò M, Euleteri P, Grollino $\mathrm{M}$, et al. The usefulness of combining traditional sperm assessments with in vitro heterospermic insemination to identify bulls of low fertility as estimated in vivo. Animal Reproduction Science. 2012;(132):17-28. doi: 10.1016/j.anireprosci.2012.04.006.

[21] Kuhn M, Hutchison J, Norman H. Modeling nuisance variables for prediction of service sire fertility. Jour Dairi Sci. 2008;(91):2823-35. doi: 10.3168/ jds.2007-0946.

[22] Rodriguez-Martinez H. Methods for sperm evaluation and their relationship to fertility. Congresso Brasileiro de Reprodução Animal; Goiânia: CBRA; 2005.p. 1-9.

[23] Rodriguez-Martinez H. Laboratory Semen Assessment and Prediction of Fertility: still Utopia? Reprod Dom Anim. 2003;(38):312-8.

[24] Graham J, Mocé E. Fertility evaluation of frozen/ thawed semen. Theriogenology. 2005;(64):492-504.

[25] Crespilho A, Freitas Dell'Aqua C, Dell Aqua Jr J. Impacto do sêmen no sucesso dos programas de IATF: métodos básicos e avançados de avaliação. 3 Simpósio Internacional de Reprodução Animal Aplicada; Londrina; 2008.p. 78-94.

[26] Freitas Dell'Aqua C, Crespilhio A, Papa F, Dell'Aqua Jr J. Metodologia de avaliação laboratorial do sêmen congelado bovino. Rev. Bras. Reprod. Anim. 2009;33(4):213-22.

[27] Rodriguez-Martinez H. Can we increase the estimative value of semen assessment? Rerpoduction in Domestic Animals. 2006;41(Suppl 2):2-10.

[28] Gonçalves PBD, Ricardo JD, De Figuerêdo FV. Biotecnicas Aplicadas à Reprodução Animal. São Paulo: Roca Ltda; 2008.

[29] Bernardi M. Tecnologias aplicadas no exame do ejaculado suíno para a produção. Acta Scientiae Veterinariae. 2008;36(1):5-16.

[30] Papa F, Crespilho A, Freitas Dell'Aqua C, Dell'Aqua Jr J. Impacto do sêmen no sucesso dos programas de IATF: métodos básicos e avançados de avaliação.
30 Simpósio Internacional De Reprodução Animal Aplicada. Londrina; 2008.p. 78-94.

[31] Hancock J, Trevan D. The acrosome and post-nuclear cap of bull spermatozoa. J. R. Microsc. Soc. 1957;(76):77-83.

[32] Saacke R. Fertility in the bovine male: current status and future prospects (an opinion). Proceedings of the 18th Technical Conference on Artificial Insemination; 2000.p. 90-6.

[33] Thundathil J, Palasz A, Mapletoft R, Barth A. An investigation of the fertilization characteristics of pyriform-shaped bovine spermatozoa. Anim Reprod Sci.1999;(57):35-50.

[34] Barth A, Oko R. Abnormal Morphology of Bovine Spermatozoa. Iowa: Iowa State University Press; 1989.

[35] Fawcett D. The mammamalian spermatozoom. Developmental Biology. 1975;(44):394-436.

[36] Blom E. The ultrastructure of some characteristic sperm defects and a proposal for a new classification of the bull spermiogram. Nord Vet Med. 1973;(25):383-91.

[37] CBRA-Colégio Brasileiro de Reprodução Animal. Manual para exame andrológico e avaliação de sêmen animal. Em: Manual para exame andrológico e avaliação de sêmen animal 3. ed. Belo Horizonte: 2013.

[38] Casagrande J, Pinheiro L, Almeida C, Patologia espermática agrupada segundo Blom (197na avaliação de sêmen para congelação. Rev Bras Reprod Anim. 1980;(3):19-23.

[39] Arruda RD, Eneiva C, Celeghini A, Andrade A, Garcia J, Nascimento C, et al. Importância da qualidade do sêmen em programas de IATF e TEFT. $1^{\circ}$ Simpósio Internacional de Reprodução Animal Aplicada. Londrina: sIRAA Edições; 2004.p. 166-79.

[40] Walters AH, Eyestone WE, Saacke RG, Pearson RE, Gwazdauskas FC. Sperm morphology and preparation method affect bovine embryonic development. Journal of Andrology. 2004;25(4):554-63.

[41] Amann RP, Hammerstedt RH. In vitro evaluation of sperm quality: an opinion. Journal of Andrology.1993;14(6):397-406

[42] Kastelic J, Thundathil J. Breeding Soundness Evaluation and Semen Analysis for Predicting Bull Fertility. Reprod Dom Anim. 2008; 43(Suppl. 2):368-73. doi: 10.1111/j.1439-0531.2008.01186.x

[43] Harrison R, Vickers S. Use of fluorescent probes to assess membrane integrity in mammalian spermatozoa. Journal of Reproduction and Fertility. 1990;88(1):343-52.

[44] Brito L, Barth A, Bilodeau-Goeseels S, Panich P. Comparison of methods to evaluate the plasmalemma of bovine sperm and their relationship with in vitro fertilization rate. Theriogenology. 2003;(60):1539-51. 
[45] Celeghini E, Arruda R, De Andrade A, Nascimento J, Raphael C. Practical techniques for bovine sperm simultaneous fluorimetric assessment of plasma, acrosomal and mitochondrial membranes. Reprod Dom Anim. 2007;(42):479-88.

[46] Jeyendran R, Van Der Ven H, Perez-Pelaez M, Crabo B, Zaneveld L. Development of an assay to assess the functional integrity of the human sperm membrane and its relationship to other semen characteristics. J Reprod Fertil. 1984;(70):219-28.

[47] Tartaglione C, Ritta M. Prognostic value of spermatological parameters as predictors of in vitro fertility of frozen-thawed bull semen. Theriogenology. 2004;(62):1245-52.

[48] Januskauskas AJ, Johannisson A, Rodriguez-Martinez $H$. Subtle membrane changes in cryopreserved bull semen in relation with sperm viability, chromatin structure, and field fertility. Theriogenology. 2003;(60):743-58.

[49] Srivastava N, Srivastava S, Ghosh S, Kumar A, Perumal P, Jerome A. Acrosome membrane integrity and cryocapacitation are related to cholesterol content of bull spermatozoa. Asian Pacific Journal of Reproduction. 2013;2(2):126-31. doi: 10.1016/S23050500(13)60132-3.

[50] Thundathil J, Palasz AB, Mapletoft R. Plasma membrane and acrosomal integrity in bovine spermatozoa with the knobbed acrosome defect. Theriogenology. 2001;(58):87-102.

[51] Chandler D, Williams J. Intracellular divalent cation release in pancreatic acinar cells during stimulus secretion coupling. I. Use of chlorotetracycline as fluorescent probe. J Cell Biol. 1978;(76):371-85.

[52] Aitken R. Sperm function tests and fertility. International Journal of Andrology. 2006;(29):69-75.

[53] Silva P, Gadella B. Detection of damage in mammalian sperm cells. Theriogenology. 2006;(65):958-78.

[54] Nagy S, Hallap T, Johannisson A, Rodriguez-Martinez $\mathrm{H}$. Changes in plasma membrane and acrosome integrity of frozen-thawed bovine spermatozoa during a $4 \mathrm{~h}$ incubation as measured by multicolor flow cytometry. Animal Reproduction Science. 2004;(80):225-35.

[55] Miki K, QU W, Goulding E, Willis W, Bunch D, Strader L, et al. Glyceraldehyde 3-phosphate dehydrogenase-S, a sperm-specific glycolytic enzyme, is required for sperm motility and male fertility. Proc Natl Acad Sci UsA. 2004;101(47):16501-6.

[56] Mukai C, Okuno M. Glycolysis plays a major role for adenosine triphosphate supplementation in mouse sperm flagellar movement. Biol Reprod. 2004;(71):540-7.
[57] Alessandra G, Lacalandra GM, Filannino A, Pizzi F, Nicassio M, Dell'Aquila ME, et al. Assessment of viability, chromatin structure stability, mitochondrial function and motility of stallion fresh sperm by using objective methodologies. Journal of Cell and Animal Biology. 2010;4(2):34-41.

[58] Garner D, Thomas C, Joerg H, DeJarnette J, Marshall C. Fluorometric assessments of mitochondrial function and viability in cryopreserved bovine spermatozoa. Biol Reprod. 1997;(57):1401-6.

[59] Hammoud SS, Nix DA, Zhang H, Purwar J, Carrell DT, Cairns BR. Distinctive chromatin in human sperm packages genes for embryo development. Nature. 2009; (460):470-9. doi: 10.1038/nature08162

[60] Aitken RJ. Whither must spermatozoa wander? The future of laboratory seminology. Asian Journal of Andrology. 2010;(12):99-103. doi: 10.1038/aja.2008.42

[61] Sakkas D, Alvarez JG. Sperm DNA fragmentation: mechanisms of origin, impact on reproductive outcome, and analysis. Fertility and Sterility. 2010;93(4):102736. doi: 10.1016/j.fertnstert.2009.10.046

[62] Rybar R, Faldikova L, Faldyna M, Machatkova MR. Bull and boar sperm DNA integrity evaluated by sperm chromatin structure assay in the Czech Republic. Vet. Med. - Czech. 2004;49(1):1-8.

[63] Aleem M, Padwal V, ChoudharI J, Balasinor N, Gill-Sharma MK. Sperm protamine levels as indicators of fertilising potential in sexually mature male rats. Andrologia. 2008;(40):29-37. doi: 10.1111/j. 1439-0272.2008.00805.x

[64] Brewer L, Corzett M, Balhorn R. Condensation of DNA by Spermatid Basic Nuclear Proteins. The Journal of Biological Chemistry. 2002;277(41),Issue 11:38895-900.

[65] McLay DW, Clarke HJ. Remodelling the paternal chromatin at fertilization in mammals. Reproduction. 2003;(125):625-33.

[66] Balhorn R. A Model for the Structure of Chromatin in Mammalian Sperm. The journal of cell biology.1982;(93):298-305.

[67] Zini A, Boman JM, Belzile E, Ciampi A. Sperm DNA damage is associated with an increased risk of pregnancy loss after IVF and ICSI: systematic review and meta-analysis. Hum Reprod. 2008;(23):2663-8. doi: 10.1093/humrep/den321

[68] Carrell DT, Wilcox AL, Lowy L, Peterson CM, Jones KP, Erickson L, Campbell B, Branch DW, Hatasaka $\mathrm{HH}$. Elevated sperm chromosome aneuploidy and apoptosis in patients with unexplained recurrent pregnancy loss. Obstet Gynecol. 2003;(101):1229-35.

[69] Aitken R, De Iuliis G. On the possible origins of DNA damage in human spermatozoa. Molecular Human 
Reproduction. 2010b;16(1):3-13. doi: 10.1093/molehr/gap059.

[70] Natali A, Turek PJ. An assessment of new sperm tests for male infertility. Urology. 2011;(77):1027-34. doi: 10.1016/j.urology.2010.10.005

[71] Evenson DP, Larson KL, Jost LK. Sperm Chromatin Structure Assay: Its clinical use for detecting sperm DNA fragmentation in male infertility and comparisons with other techniques. Journal of Andrology. 2002;23(1):25-43

[72] Erenpreiss J, Spano M, Erenpreisa J, Bungum M, Giwercman A. Sperm chromatin structure and male fertility: biological and clinical aspects. Asian J Androl. 2006;8(1):11-29.

[73] Januskauskas AJ, Rodriguez-Martinez H. Assessment of sperm quality through fluorometry and sperm chromatin structure assay in relation to field fertility of frozen thawed semen from swedish AI bulls. Theriogenology. 2001;(55):947-61.

[74] Garcia-Macias V, De Paz P, Martinez-Pastor F, Alvarez $\mathrm{M}$, Gomes-Alves S, Bernardo J, et al. DNA fragmentation assessment by flow cytometry and SpermBos-Halomax (bright-field microscopy and fluorescence microscopy) in bull sperm. Int J Androl. 2006;(30):88-98.

[75] Martínez-Pastor F, Fernández-Santos DR, Domínguez-Rebolledo A, Esteso M, Garde J. DNA Status on Thawed Semen from Fighting Bull: A Comparison Between the SCD and the SCSA Tests. Reprod Dom Anim. 2009;(44):424-31. doi: 10.1111/j.1439-0531.2008.01098.x

[76] Hallap T. Assessment of sperm attributes of frozenthawed AI doses from Swedish and Estonian dairy bulls sires. Division of comparative reproduction, obstetrics and udder health [Tese de doutorado]. Upsala: Department of Clinical Sciences - Swedish University of Agricultural Sciences; 2005.

[77] Zhang B, Larsson BNL, Rodríguez-Martíinez H. Relationship between embryo o development in vitro and 5 day non-return rates of frozen-thawed semen from dairy AI bulls. Theriogenology. 1997;(48):221-31.

[78] Schneider CS, Ellington JE, Wright Jr RW. Relationship between bull field fertility and in vitro embryo production using sperm preparation methods with and without somatic cell co-culture. Theriogenology. 1999;(51):1085-98.

[79] Zhang BR, Larsson B, Lundeheim N, Haard MG, Rodriguez-Martinez H. Prediction of bull fertility by combined in vitro assessments of frozen-thawed semen from young dairy bulls entering an AI-programme. Int J Androl. 1999;22(4):253-60.
[80] Al Naib A, Hanrahan J, Lonergan P, Fair S. In vitro assessment of sperm from bulls of high and low field fertility. Theriogenology. 2011;(76):161-7. doi: 10.1016/j.theriogenology.2010.10.038

[81] Morado S, Pereyra V, Breininger E, Sara R, Cetica P. Study of sperm evaluation parameters to estimate cryopreserved bovine semen fertility. Austin J Vet Sci Anim Husb. 2015;2 Issue 1-4.

[82] Kadarmideen HN. Genomics to systems biology in animal and veterinary sciences: Progress, lessons and opportunities. Livestock Science. 2014;(166):232-48. doi:10.1016/j.livsci.2014.04.028

[83] Bonilla E, XU EY. Identification and characterization of novel mammalian spermatogenic genes conserved from fly to human. MHR-Basic Science of Reproductive Medicine. 2008;14(3):137-42. doi: 10.1093/ molehr/gan002

[84] Li G, Peñagaricano F, Weigel KA, Zhang Y, Rosa G, Khatib H. Comparative genomics between fly, mouse, and cattle identifies genes associated with sire conception rate . J. Dairy Sci. 2012;95:6122-9. doi: 10.3168/jds.2012-5591

[85] Park Y-J, KIM J, You Y-A, Pang M-G. proteomic revolution to improve tools for evaluating male fertility in animals. J Proteome Res. 2013;12(11):4738-47. doi: 10.1021/pr400639x.

[86] Roncoletta M, Carvalho EM, Esper CR, Barnabe VH, Franceschini PH. Fertility-associated proteins in Nelore Bull sperm membranes. Animal Reproduction Science. 2006;(91):77-87.

[87] Killian G. Fertility-associated proteins in male and female reproductive fluids of cattle. Anim. Reprod. 2012;9(4):703-12.

[88] D’Amours O, Frenette G, Fortier M, Leclerc P. Sullivan R. Proteomic comparison of detergent-extracted sperm proteins. Reproduction. 2010;139(3):545-56. doi: 10.1530/REP-09-0375

[89] Park Y-J, Kwon W-S, Oh S-A, Pang M-G. Fertility -related proteomic profiling bull spermatozoa separated by percoll. J. Proteome Res. 2012;2(11):4162-8. doi: $10.1021 / \mathrm{pr} 300248 \mathrm{~s}$

[90] Jodar M, Selvaraju S, Sendler E, Diamond MP, Krawetz SA. The presence, role and clinical use of spermatozoal RNAS. Human Reproduction Update. 2013;19(6):604-24. doi: 10.1093/humupd/dmt031

[91] Rahman MS, Lee J-SKwon W-S, Pang M-G. Sperm proteomics: road to male fertility and contraception. International JournalofEndocrinology.2013;(2013):111. doi:http://dx.doi.org/10.1155/2013/360986

[92] Fortes MR, Deatley KL, Lehnert SA, Burns BM, Reverter A, Hawken RJ, et al. Genomic regions associated 
with fertility traits in male and female cattle: Advances from microsatellites to high-density chips and beyond. Animal Reproduction Science. 2013;(141):119. doi: 10.1016/j.anireprosci.2013.07.002.

[93] Cochran SD, Cole JB, Null DJ, Hansen PJ. Discovery of single nucleotide polymorphisms in candidate genes associated with fertility and production traits in Holstein cattle. BMC Genetics. 2013;14:(49):1-23. doi: 10.1186/1471-2156-14-49.

[94] Santos DJ, Peixoto MG, Tonhati AH, Carvalho MR, Silva MV. Análise de associação global para identificar locos relacionados às produções de leite, de gordura e de proteína na raça Guzerá. X Simpósio Brasileiro de Melhoramento Animal; Uberaba, sBmA; 2013.

[95] Casas E, Ford JJ, Roher GA. Quantitative Genomics of Male Rerpoduction. Em: Jiang Z, Ott TL. Reproductive Genomics in Domestic Animals. Iowa: Blackwell Publishing; 2010.p. 458.
[96] Feugang JM, Kaya A, Page GP, Chen L, Mehta T, Hirani K, et al. Two-stage genome-wide association study identifies integrin beta 5 as having potential role in bull fertility. BMC Genomics. 2009;(10):176. doi: 10.1186/1471-2164-10-176.

[97] Fortes MR, Reverter A, Hawken RJ, Bolormaa S, Lehnert AS. Candidate genes associated with testicular development, sperm quality, and hormone levels of inhibin, luteinizing hormone, and insulin-like growth factor 1 in brahman bulls. Biology of Reproduction. 2012;87(3):(58),1-8. doi: 10.1095/biolreprod.112.101089

[98] Chenoweth P. Effects of the male on the embryo. Revista Brasileira de Reprodução Animal. 2011;35(2):154-9.

[99] Khatib H. Single nucleotide polymorphisms associated with bull fertility. 2015;Patente n. 2015030794. Estados Unidos. 